\title{
BMJ Open Comparing physical assessment with administrative data for detecting pressure ulcers in a large Canadian academic health sciences centre
}

\author{
Chantal Backman, ${ }^{1,2}$ Saskia E Vanderloo, ${ }^{3}$ Toba B Miller, ${ }^{4}$ Lisa Freeman, ${ }^{5}$ \\ Alan J Forster ${ }^{3,6}$
}

To cite: Backman C, Vanderloo SE, Miller TB, et al. Comparing physical assessment with administrative data for detecting pressure ulcers in a large Canadian academic health sciences centre. BMJ Open 2016;6:e012490. doi:10.1136/bmjopen-2016012490

- Prepublication history for this paper is available online. To view these files please visit the journal online (http://dx.doi.org/10.1136/ bmjopen-2016-012490).

Received 2 May 2016 Revised 6 July 2016 Accepted 8 September 2016 CrossMark

For numbered affiliations see end of article.

Correspondence to Professor Chantal Backman; chantal.backman@uottawa.ca

\section{ABSTRACT}

Objective: This study aimed to compare classification of pressure ulcers from administrative data with a gold standard assessment, specifically; pressure ulcers confirmed by an independent physical assessment performed by trained nurse surveyors.

Setting: A retrospective analysis of pooled crosssectional samples of inpatients assessed across 3 consecutive prevalence surveys in a large academic health sciences centre between 2012 and 2013.

Participants: There were 2001 patients for whom physical and chart assessments were completed, and for whom a discharge abstract was also available at the time of analysis. The cohort's mean age was 65 years and $55 \%$ were women.

Results: Based on the physical assessment findings, $14.6 \%$ of patients $(n=292)$ had at least 1 pressure ulcer, with a total of 345 pressure ulcers documented among these patients: (stage $\mathrm{I}=162$; stage $\|=120$; stage III=22; stage IV=22 and unstageable=19). Based on coded information, 78 (3.9\%) of patients had a pressure ulcer. Of patients with a pressure ulcer determined by the physical assessment, only $21 \%$ also had a pressure ulcer captured in the administrative data. Furthermore, only $6 \%$ of the patients with a hospital-acquired pressure ulcer, stage II or greater determined by the physical assessment were coded in the Discharge Abstract Database (DAD).

Conclusions: The results of this study demonstrate that coding in the DAD may under-report and fail to accurately reflect the true burden of pressure ulcers in hospitalised patients. This may occur because the presence of pressure ulcers is currently documented in the health record by nurses and not by physicians, yet the administrative data recorded in the DAD only includes physician documented pressure ulcers. We recommend enhancements to the coding methods to monitor and report on pressure ulcers.

\section{INTRODUCTION}

Pressure ulcers are a significant issue among hospitalised patients worldwide. In the Canadian context, the estimated prevalence

\section{Strengths and limitations of this study}

- We studied a large number of patients in a large academic health sciences centre using the physical assessment as the gold standard comparator. There are no other similar studies of this important problem.

- We compared any pressure ulcer observed on prevalence day to any pressure ulcer documented in the administrative data.

- We compared two different types of prevalence estimates: cross-sectional and period prevalence. Owing to the nature of each type of prevalence estimate, the sample population may have been different between each group with longer stay patients being over-represented in the crosssectional prevalence.

ranges from $23.9 \%$ to $29.7 \%$ among acute care patients. ${ }^{1}$ Avoiding skin breakdown and the development of pressure ulcers is a recognised priority for ensuring quality of care and potential cost-savings. ${ }^{2}$ According to the US-based National Pressure Ulcer Advisory Panel (NPUAP), the cost of caring for pressure ulcers has been estimated at over US $\$ 11$ billion per year. Since pressure ulcers are for the most part preventable, there is a need to identify the at-risk populations and to target early intervention strategies. Despite an increased awareness surrounding the burden of pressure ulcers and the importance of prevention and treatment, there is a lack of accurate populationbased methods to detect and monitor pressure ulcer rates. This creates challenges for the measurement of outcomes following efforts to prevent and reduce pressure ulcers over time.

Administrative data are one source for estimating pressure ulcer incidence and prevalence. Each inpatient hospital encounter is 
summarised on discharge through abstracts submitted to the Discharge Abstract Database (DAD), based on the Coding Standards for the International Classification for Diseases and Related Health Problems, 10th Revision (ICD-10). Each diagnosis recorded in the DAD must be coded according to ICD-10, and assigned a Diagnosis Type Code, representing the influence of the condition on the patient's treatment. ${ }^{3}$ According to these standards, diagnosis code and diagnosis type are taken directly from the physician's documentation. DAD coding and diagnosis typing may also be sought from the documentation of other healthcare professionals, but only if they have been designated with primary responsibility for the patient's care. ${ }^{3}$ Further complicating the coding is the fact that the staging system used for coding in the DAD may differ from the NPUAP staging guidelines that are followed by the majority of nurses and other healthcare professionals in Canada. ${ }^{4}$

Owing to the potential variation in documentation practices between healthcare professionals and the provider specifications in the coding guidelines, we hypothesised that the current estimates of pressure ulcers based on these administrative codes likely do not accurately reflect the true burden of this condition. ${ }^{5}$ If the information in the DAD does not accurately capture the pressure ulcers, this can have a significant impact on healthcare policy that often relies on statistical information from these types of electronic sources. Therefore, the overall aim of this study was to compare classification of pressure ulcers from the DAD with a gold standard assessment, specifically, pressure ulcers confirmed by an independent physical assessment performed by trained nurse surveyors.

\section{METHODS}

\section{Study design and setting}

This study involved a retrospective analysis of pooled cross-sectional samples of inpatients at a Canadian academic health sciences centre with more than 1127 inpatient beds. We received Research Ethics Board approval to use these data for research purposes.

\section{Participants}

All patients who were admitted and assessed on 1 of 3 consecutive prevalence survey days between 2012 and 2013 were included. Each prevalence survey consisted of a 1-day cross-sectional survey where nurse surveyors collected data from inpatients' health records (ie, a chart assessment) and performed a physical assessment of all inpatients. The content of the survey was selected to identify patients at risk of developing pressure ulcers, to determine the presence of pressure ulcers, and to assess health providers' adherence to the hospital's policies and programmes. The number of pressure ulcers, their location and their severity 'stage' (according to the NPUAP definitions that were in effect during the study periods) were recorded for each patient. These were further classified as 'developed in hospital' or 'present on admission', based on the results of the chart assessment. All surveyors received standard training on staging pressure ulcers. On the survey day enterostomal therapy nurses, specialists in wound care, were also available to help with staging pressure ulcers if needed. There has been similar prevalence surveys conducted since 1993 to provide information on the presence and severity of pressure ulcers, among other conditions. For purposes of this analysis, we used the data from 2012 to 2013 because the data from these 2 years were available electronically. ${ }^{6}$

The case selection process is described in figure 1. We pooled data from patients who were present on 1 of the 3 consecutive prevalence days (25 April 2012, 21 November 2012 and 25 April 2013). A small number of patients did not undergo a physical or chart assessment for various reasons (eg, patient was receiving a procedure at the time of the prevalence survey or the patient's chart was not available at the time of survey). We excluded these patients. If a patient was in the hospital on more than one prevalence survey day, or if a patient's discharge abstract was not available at the time of analysis (ie, where a patient was still in hospital, or the discharge abstract was not complete) they were also excluded. Each of the included patient encounters was also summarised in an abstract that was submitted to the DAD and that included a diagnostic code (ICD-10 classification) and a diagnostic type (eg, M: most responsible diagnosis; type 1: preadmission comorbidity; type 2: postadmission comorbidity). ${ }^{3}$

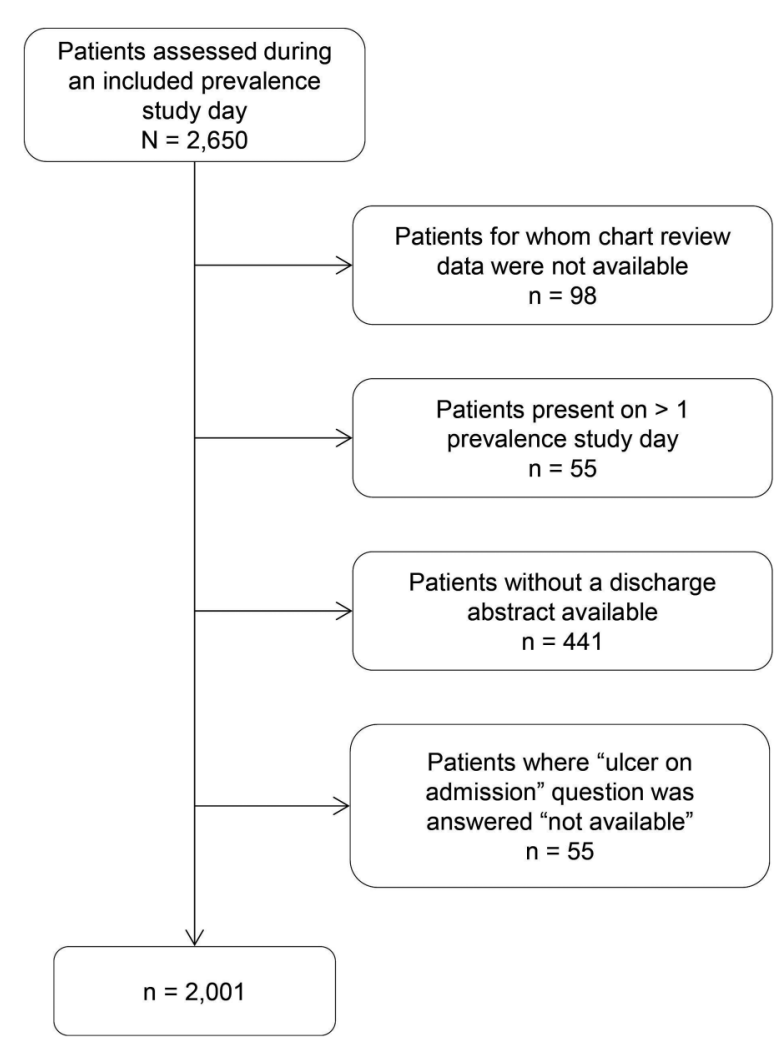

Figure 1 Derivation of study cohort. 


\section{Analysis}

To assess the accuracy of administrative data in identifying pressure ulcers among patients discharged from hospital, we compared pressure ulcer cases identified in the DAD against 'nurse-confirmed' pressure ulcers that were assessed and documented on 1 of the 3 prevalence days. The analysis was divided into three parts. First, we compared patients with any pressure ulcer identified on prevalence day to any pressure ulcer coded in the corresponding DAD records (ICD-10 codes: L89.0-L89.9). Second, we narrowed the analyses to patients with a pressure ulcer that developed after admission only, compared with pressure ulcers coded as a type 2 diagnosis in the DAD record (ie, postadmission comorbidity). Third, we further limited the comparison to patients with a stage II pressure ulcer developed in hospital against pressure ulcers coded as type 2 diagnoses in the corresponding DAD records. Stage I pressure ulcers may not be recognised or documented as frequently as the more severe stages of the condition, ${ }^{7} 8$ and therefore we expected higher agreement between the prevalence data and the DAD when we limited the analyses to stage II pressure ulcers and above.

We calculated the sensitivity, specificity, positive predictive value and negative predictive value for each of the comparisons, using the nurse-confirmed physical assessment as the 'gold standard'. We also calculated the $\kappa$ statistic and $95 \%$ CIs to account for the level of agreement due to chance, where a $\kappa$ of 1.0 would indicate perfect agreement and a $\kappa$ of 0.0 would indicate agreement based on chance alone. ${ }^{9}$ We described the study population using basic demographic variables and clinical characteristics. We also calculated the Elixhauser Comorbidity Score developed by van Walraven et $a l^{10}$ to summarise the comorbidity in this patient sample.

The data analysis for this study was generated using SAS software, V.9.3, 2011 SAS Institute, SAS and all other SAS Institute product or service names are registered trademarks or trademarks of SAS Institute, Cary, North Carolina, USA.

\section{RESULTS}

Across 3 consecutive prevalence days, there were 2001 patients for whom physical and chart assessments were completed, and for whom a discharge abstract was also available at the time of analysis (figure 1). The cohort's mean age was 65 years and $55 \%$ were women. The cohort is described further in table 1.

Based on the physical assessment findings, $14.6 \%$ of patients $(n=292)$ had at least 1 pressure ulcer, with a total of 345 pressure ulcers documented among these patients: stage $\mathrm{I}=162$; stage $\mathrm{II}=120$; stage $\mathrm{III}=22$; stage $\mathrm{IV}=22$ and unstageable $=19$ (ie, some patients had multiple pressure ulcers). In contrast, the results from the coded information showed that only 78 (3.9\%) of patients had any pressure ulcer. Table 2 provides the prevalence of pressure ulcers among the prevalence

\begin{tabular}{|c|c|}
\hline Total patients & $\mathrm{N}=2001^{*}$ \\
\hline \multicolumn{2}{|l|}{ Age (years) } \\
\hline Mean & $65.1 \pm 18.6$ \\
\hline Median & $68(53-80)$ \\
\hline \multicolumn{2}{|l|}{ Gender } \\
\hline $\mathrm{F}$ & 1099 (54.9) \\
\hline $\mathrm{M}$ & $902(45.1)$ \\
\hline \multicolumn{2}{|l|}{ Department } \\
\hline Medicine & $897(44.8)$ \\
\hline Surgery & $744(37.2)$ \\
\hline Other & $122(6.1)$ \\
\hline Obstetrics/gynaecology/newborn care & $120(6.0)$ \\
\hline Family practice & $118(5.9)$ \\
\hline \multicolumn{2}{|l|}{ Elixhauser score } \\
\hline Mean & $4.9 \pm 6.4$ \\
\hline Median & $3(0-8)$ \\
\hline \multicolumn{2}{|l|}{ Total LOS (days) } \\
\hline Mean & $30.1 \pm 48.3$ \\
\hline Median & $15(6-31)$ \\
\hline \multicolumn{2}{|l|}{ Acute LOS (days) } \\
\hline Mean & $19.7 \pm 29.1$ \\
\hline Median & $12(6-23)$ \\
\hline \multicolumn{2}{|c|}{$\begin{array}{l}\text { Continuous characteristics are presented with the mean } \pm S D \text { and } \\
\text { median (IQR). } \\
\text { ALC patients are those who no longer require acute care services } \\
\text { and are waiting to be discharged to a suitable care setting in the } \\
\text { community. } \\
\text { 'Categorical characteristics are presented with percentages. } \\
\text { Acute LOS (total LOS) - (days spent in 'ALC' status). } \\
\text { ALC, alternate level of care; F, female; LOS, length of stay; M, } \\
\text { male. }\end{array}$} \\
\hline
\end{tabular}

Table 2 Pooled data from three consecutive prevalence surveys

\begin{tabular}{ll}
\hline Patients with physical assessment & $\begin{array}{l}\mathbf{N}=2001 \\
\text { (\%) }\end{array}$ \\
\hline Patients with at least one pressure ulcer & $292(14.6)$ \\
Developed while in hospital, any stage & $201(10.0)$ \\
Developed while in hospital, stage II or & $89(4.4)$ \\
greater & \\
\hline
\end{tabular}

sample and table 3 provides the prevalence of pressure ulcers as coded in the DAD.

Of the nurse-confirmed cases, only 21\% (n=61) were captured in the administrative data; however, only a small percentage $(1 \%)$ of patients with a pressure ulcer coded in the DAD did not have a pressure ulcer on prevalence day (either not present, not observed or it may have developed later; table 4).

The agreement between the two sources decreased when we analysed the sample by patients who developed a pressure ulcer after admission compared with patients with a type 2 diagnosis code in the DAD (postadmission comorbidity; table 5). Only $4 \%(n=8)$ of the patients with a pressure ulcer that developed in hospital were also coded in DAD as a type 2 diagnosis. 
Table 3 DAD records corresponding to patients observed on one of three consecutive prevalence surveys

\begin{tabular}{|c|c|c|}
\hline \multicolumn{2}{|l|}{ DAD records } & \multirow[t]{2}{*}{$\mathrm{N}=2001(\%)$} \\
\hline ICD-10 code & $\begin{array}{l}\text { Patients with at least one } \\
\text { code for: }\end{array}$ & \\
\hline L89.0-L89.9 & Pressure ulcer, any stage & $78(3.9)$ \\
\hline L89.1-L89.9 & $\begin{array}{l}\text { Pressure ulcer, } \\
\text { stage II or greater }\end{array}$ & $71(3.5)$ \\
\hline \multicolumn{3}{|c|}{ Diagnosis type } \\
\hline Type 1 & $\begin{array}{l}\text { Pressure ulcer developed } \\
\text { while in hospital }\end{array}$ & $16(0.8)$ \\
\hline Type 2 & Pressure ulcer on admission & $45(2.2)$ \\
\hline
\end{tabular}

Table 4 Patients with a pressure ulcer present on physical assessment, compared with patients with a pressure ulcer coded in the DAD

\begin{tabular}{cccr}
\hline \multicolumn{4}{c}{ Pressure ulcer on assessment } \\
\cline { 2 - 4 } & Yes & No & Total \\
\hline Any ICD-10 & pressure ulcer code & & \\
Yes & 61 & 17 & 78 \\
No & 231 & 1692 & 1923 \\
Total & 292 & 1709 & 2001 \\
\hline
\end{tabular}

$\mathrm{Sn}=0.21 ; \mathrm{Sp}=0.99 ; \mathrm{PPV}=0.78 ; \mathrm{NPV}=0.88 ; \kappa=0.29(95 \% \mathrm{Cl} 0.23$ to 0.35 .

DAD, Discharge Abstract Database; ICD-10, International Classification for Diseases and Related Health Problems, 10th Revision; NPV, negative predictive value; PPV, positive predictive value; $\mathrm{Sn}$, sensitivity; $\mathrm{Sp}$, specificity.

Table 5 Patients who developed a pressure ulcer while in hospital, compared with patients with a type 2 pressure ulcer coded in the DAD

\begin{tabular}{|c|c|c|c|}
\hline & \multicolumn{3}{|c|}{$\begin{array}{l}\text { Pressure ulcer developed while in } \\
\text { hospital }\end{array}$} \\
\hline & Yes & No & Total \\
\hline \multicolumn{4}{|c|}{ Any type 2 ICD-10 pressure ulcer code } \\
\hline Yes & 8 & 8 & 16 \\
\hline No & 193 & 1792 & 1985 \\
\hline Total & 201 & 1800 & 2001 \\
\hline \multicolumn{4}{|c|}{$\begin{array}{l}\mathrm{Sn}=0.04 ; \mathrm{Sp}=1.00 ; \mathrm{PPV}=0.50 ; \mathrm{NPV}=0.90 ; \kappa=0.06(95 \% \mathrm{Cl} 0.01 \\
\text { to 0.10). } \\
\text { DAD, Discharge Abstract Database; ICD-10, International } \\
\text { Classification for Diseases and Related Health Problems, 10th } \\
\text { Revision; NPV, negative predictive value; PPV, positive predictive } \\
\text { value; Sn, sensitivity; Sp, specificity. }\end{array}$} \\
\hline
\end{tabular}

Furthermore, only $7 \% \quad(n=6)$ of the patients with at least one pressure ulcer stage II or greater that developed in hospital and was observed through physical assessment were also coded in DAD (table 6). The $\mathrm{\kappa}$ observer agreement calculations identified, at best, 'fair' agreement between the two sources $(\kappa=0.29)$, but otherwise showed only 'slight' agreement between the two
Table 6 Patients who developed a stage II or greater pressure ulcer while in hospital, compared with patients with a type 2 pressure ulcer coded in the DAD

\begin{tabular}{|c|c|c|c|}
\hline & \multicolumn{3}{|c|}{$\begin{array}{l}\text { Pressure ulcer stage II or greater } \\
\text { developed while in hospital }\end{array}$} \\
\hline & Yes & No & Total \\
\hline \multicolumn{4}{|c|}{ Any type 2 ICD-10 pressure ulcer code } \\
\hline Yes & 6 & 10 & 16 \\
\hline No & 83 & 1902 & 1985 \\
\hline Total & 89 & 1912 & 2001 \\
\hline \multicolumn{4}{|c|}{$\begin{array}{l}\mathrm{S} n=0.07 ; \mathrm{Sp}=0.99 ; \mathrm{PPV}=0.38 ; \mathrm{NPV}=0.96 ; \kappa=0.10(95 \% \mathrm{Cl} 0.02 \\
\text { to } 0.18) \text {. } \\
\text { DAD, Discharge Abstract Database; ICD-10, International } \\
\text { Classification for Diseases and Related Health Problems, } 10 \text { th } \\
\text { Revision; NPV, negative predictive value; PPV, positive predictive } \\
\text { value; Sn, sensitivity; Sp, specificity. }\end{array}$} \\
\hline
\end{tabular}

detection methods, according to the categories presented by Landis and Koch. ${ }^{11}$

\section{DISCUSSION}

The results of this study suggest that a large proportion of pressure ulcers may not be captured in the administrative data that are routinely collected to summarise a patient's stay in hospital. This is consistent with a recent study by Meddings et a $\tilde{e}$ which found that administrative data were a poor indicator of pressure ulcer performance in a large sample of California hospitals, compared with pressure ulcers detected through surveillance. The inconsistencies identified by the authors highlight why pressure ulcer rates from administrative data are underreported and are unlikely suitable for performance benchmarking efforts. These shortcomings in the administrative data are, in part, related to poor pressure ulcer documentation practices in the patient record. In Sweden, Gunningberg and Ehrenberg ${ }^{7}$ found that paper-based pressure ulcer documentation was poor, but that documentation improved with the implementation of an electronic health record. ${ }^{12}$ In the USA, Dahlstrom $e t a l^{13}$ found an opposite effect with respect to the completeness of documentation, when documentation was moved to an electronic system; however, this trend subsequently reversed for nurses, but not among physicians.

A potential explanation for the differences observed between the prevalence survey data and the DAD relates to who was documenting the pressure ulcer. This is largely due to the fact that pressure ulcers are routinely documented by nurses and not by physicians. In the USA, Arora $e t a l^{14}$ observed that the rate of pressure ulcer risk assessment among nurses was $100 \%$, compared with just under 3\% among physicians, and that physicians documented fewer than one out of every two pressure ulcers identified by nurses. In a related study by Dahlstrom et $a l^{13}$ following a campaign to improve pressure ulcer documentation, researchers observed that nurses documented almost all pressure ulcers (96.7\%) compared with significantly fewer documented by 
physicians $(70.6 \%)$. This difference increased when the researchers considered 'complete' documentation, only (46.2\% and $15.2 \%$ among nurses and physicians, respectively). Therefore, if nurse documentation is not being considered when pressure ulcers are being coded, then the administrative data are likely missing a large proportion of these cases.

However, in the same study, the authors noted that even after the intervention, fewer than half of the cases documented by nurses contained 'complete' information (ie, size, location and stage). ${ }^{13}$ In Iceland, Thoroddsen et $a l^{15}$ also observed that size and category were documented $11 \%$ and $55 \%$ of the time, respectively, for recorded pressure ulcers, but found that location was documented more consistently (88\%). Similarly, Gunningberg and Ehrenberg $^{7}$ found that nursing documentation captured pressure ulcer location $96.6 \%$ of the time, but only captured size $15 \%$ of the time and category was not documented in any of the records. Therefore, although there is evidence that nurses document pressure ulcers more often than physicians, the quality of the documentation, overall, may still be lacking.

A few limitations should be considered when interpreting our study's results. The main limitation is that we compared any pressure ulcer observed on prevalence day to any pressure ulcer documented in the administrative data. Therefore, it is possible that we recorded agreement between the two sources whereas, in reality, the pressure ulcers were mutually exclusive.

A related limitation is that we compared two different types of prevalence estimates: cross-sectional and period prevalence. In general, cross-sectional prevalence studies are limited because they represent a single point in time. When patients are sampled in this way, those who are in hospital longer are more likely to be sampled during the course of their stay than those with a shorter length of stay. Therefore, if a condition being studied is related to a longer length of stay, patients with this condition will be over-represented in a cross-sectional sample. ${ }^{16}$ Given that pressure ulcers are an example of a condition that can extend a patient's length of stay, ${ }^{17} 18$ and where a longer length of stay can also increase the risk of developing the condition, ${ }^{2}$ the prevalence of pressure ulcers measured on each prevalence day is likely to overestimate the prevalence of this condition. Further, if pressure ulcer severity is associated with additional increases in the length of stay, then a higher proportion of severe cases would likely be observed on a prevalence day. Then, if severe pressure ulcers are documented more often, ${ }^{78}$ the correlation between the administrative data and observed pressure ulcers would also appear to be higher. This cross-sectional sampling bias likely also explain why the total and acute length of stay for this sample are longer than the hospital's average length of stay (8.5 days, in 2012-2013)..$^{19}$

Our results should be considered in further iterations of the standards used to code pressure ulcers. In its current state, the ICD-10 mandates that diagnosis and diagnosis type are taken directly from the physician's documentation. Further investigation regarding how DAD coding and diagnosis typing for pressure ulcers can be more reflective of documentation by other healthcare professionals should be considered. Agreement on a common staging system for coding that aligns with the NPUAP guidelines would likely also improve the quality of the documentation. Further research is needed to understand if nursing documentation can improve the accuracy of pressure ulcer reporting and to design targeted quality improvement work.

\section{CONCLUSION}

The results of this study demonstrate that coding in the DAD may not accurately reflect the burden of hospital-acquired pressure ulcers. We recommend enhancements to the coding methods used to monitor and report on pressure ulcers by standardising the staging system used, and by considering the use of documented pressure ulcers by other healthcare professionals. With good benchmarking data, organisations will ultimately be able to design quality improvement strategies to prevent the development of hospital-acquired pressure ulcers and accurately evaluate the impact of the strategies.

\section{Author affiliations}

${ }^{1}$ Faculty of Health Sciences, School of Nursing, University of Ottawa, Ottawa, Ontario, Canada

${ }^{2}$ Ottawa Hospital Research Institute, Ottawa, Ontario, Canada

${ }^{3}$ Clinical Epidemiology Program, Ottawa Hospital Research Institute, Ottawa, Ontario, Canada

${ }^{4}$ Wound and Ostomy Team, Advanced Practice Nurse, Wound, Ostomy and

Rehabilitation, The Ottawa Hospital, Ottawa, Ontario, Canada

${ }^{5}$ Department of Nursing Best Practices, The Ottawa Hospital, Ottawa, Ontario,

Canada

${ }^{6}$ University of Ottawa, Ottawa, Ontario, Canada

Contributors CB designed the project, performed data acquisition, analysis and interpretation. She also drafted the article. SEV participated in project design, data acquisition and interpretation of data. She also critically appraised and edited the manuscript. TBM and LF participated in interpretation of data and critical appraisal of the manuscript. AJF designed the project, performed data acquisition, analysis and interpretation. He also critically appraised and revised the manuscript.

Funding This research received no specific grant from any funding agency in the public, commercial or not-for-profit sectors.

Competing interests None declared.

Ethics approval The Ottawa Hospital Research Ethics Board.

Provenance and peer review Not commissioned; externally peer reviewed.

Data sharing statement No additional data are available.

Open Access This is an Open Access article distributed in accordance with the Creative Commons Attribution Non Commercial (CC BY-NC 4.0) license, which permits others to distribute, remix, adapt, build upon this work noncommercially, and license their derivative works on different terms, provided the original work is properly cited and the use is non-commercial. See: http:// creativecommons.org/licenses/by-nc/4.0/ 


\section{REFERENCES}

1. Woodbury MG, Houghton PE. Prevalence of pressure ulcers in Canadian healthcare settings. Ostomy Wound Manage 2004;50:22-39.

2. Allman RM, Goode PS, Burst N, et al. Pressure ulcers, hospital complications, and disease severity: impact on hospital costs and length of stay. Adv Wound Care 1999;12:22-30.

3. Canadian Institute for Health Information. Canadian coding standards for version 2012 ICD-10-CA and CCI, revised September 2012. Ottawa, ON: CIHI, 2012.

4. Black J, Baharestani MM, Cuddigan J, et al. National Pressure Ulcer Advisory Panel's updated pressure ulcer staging system. Adv Skin Wound Care 2007;20:269-74.

5. Meddings JA, Reichert $\mathrm{H}$, Hofer $\mathrm{T}$, et al. Hospital report cards for hospital-acquired pressure ulcers: how good are the grades? Ann Intern Med 2013;159:505-13.

6. Backman C, Vanderloo S, Momtahan K, et al. Implementation of an electronic data collection tool to monitor nursing-sensitive indicators in a large academic health sciences centre. Nurs Leadersh (Tor Ont) 2014;28:77-91.

7. Gunningberg L, Ehrenberg A. Accuracy and quality in the nursing documentation of pressure ulcers: a comparison of record content and patient examination. J Wound Ostomy Continence Nurs 2004;31:328-35.

8. Defloor T, Schoonhoven L, Katrien V, et al. Reliability of the European pressure ulcer advisory panel classification system. $J$ Adv Nurs 2006;54:189-98.

9. Viera AJ, Garrett JM. Understanding interobserver agreement: the kappa statistic. Fam Med 2005;37:360-3.
10. van Walraven $C$, Austin PC, Jennings A, et al. A modification of the Elixhauser comorbidity measures into a point system for hospital death using administrative data. Med Care 2009;47:626-33.

11. Landis JR, Koch GG. Measurement of observer agreement for categorical data. Biometrics 1977;33:159-74.

12. Gunningberg L, Dahm MF, Ehrenberg A. Accuracy in the recording of pressure ulcers and prevention after implementing an electronic health record in hospital care. Qual Saf Health Care 2008;17:281-5.

13. Dahlstrom $\mathrm{M}$, Best $\mathrm{T}$, Baker $\mathrm{C}$, et al. Improving identification and documentation of pressure ulcers at an urban academic hospital. Jt Comm J Qual Patient Saf 2011;37:123.

14. Arora VM, Johnson M, Olson J, et al. Using assessing care of vulnerable elders quality indicators to measure quality of hospital care for vulnerable elders. J Am Geriatr Soc 2007;55:1705-11.

15. Thoroddsen A, Sigurjónsdóttir G, Ehnfors M, et al. Accuracy, completeness and comprehensiveness of information on pressure ulcers recorded in the patient record. Scand J Caring Sci 2013;27:84-91.

16. Rothman KJ, Greenland S, Lash T. Types of epidemiologic studies. In: Rothman KJ, Greenland S, Lash T, eds. Modern epidemiology. 3rd edn. Philadelphia: Lippincott Williams \& Wilkins, 2008:87-99.

17. Graves N, Birrell F, Whitby M. Effect of pressure ulcers on length of hospital stay. Infect Control Hosp Epidemiol 2005;26:293-7.

18. Lyder $\mathrm{CH}$, Wang $\mathrm{Y}$, Metersky $\mathrm{M}$, et al. Hospital-acquired pressure ulcers: results from The National Medicare patient safety monitoring system study. J Am Geriatr Soc 2012;60:1603-8.

19. The Ottawa Hospital 2012-2013 Annual Report. http://www. worldclasscare.ca/2013/at-a-glance/ (accessed 24 Jun 2016). 